\title{
ANALISIS PUSHOVER TERHADAP FONDASI TOWER SUTET
}

\author{
Edwardus Emmanuel S. ${ }^{1}$, Giovanni Pranata ${ }^{2}$, dan Amelia Yuwono ${ }^{3}$ \\ ${ }^{1}$ Program Studi Sarjana Teknik Sipil, Universitas Tarumanagara, Jl.Letjen S. Parman No.1 Jakarta \\ Email: edward_emmanuel88@yahoo.co.id \\ ${ }^{2}$ Program Studi Sarjana Teknik Sipil, Universitas Tarumanagara, Jl.Letjen S. Parman No.1 Jakarta \\ Email: Giovannip@ft.untar.ac.id \\ ${ }^{3}$ Program Studi Sarjana Teknik Sipil, Universitas Tarumanagara, Jl.Letjen S. Parman No.1 Jakarta \\ Email: amelia774@yahoo.com
}

\begin{abstract}
ABSTRAK
Sebagai pemasok listrik utama, PT PLN(Perusahaan Listrik Negara) terus mengembangkan jaringan transmisi sebagai bentuk pengembangan sistem kelistrikan di Indonesia. Dengan adanya kebutuhan listrik tersebut, Pemerintah memberikan pasokan listrik kepada masyarakat yang berupa sistem sumber listrik menggunakan konstruksi tower Saluran Udara Tegangan Ekstra Tinggi (SUTET). Untuk membangun sebuah konstuksi seperti tower SUTET diperlukannya fondasi yang kuat untuk memikul beban dari Suatu bangunan. Dengan melakukan Analisa statis non-linear (pushover analysis) digunakan untuk mengetahui perilaku tiang pondasi akibat gempa besar dan merupakan salah satu performance based design dengan konsep memberikan suatu pola beban lateral statik terhadap tiang fondasi secara bertahap sampai memenuhi target perpindahan lateral yang direncanakan.
\end{abstract}

Kata kunci: metode spektrum kapasitas, analisis pushover, pondasi tower, tower SUTET, analisa statis non-linier.

\section{PENDAHULUAN}

\section{Latar belakang}

Pada umumnya Fondasi terdiri dari 2 jenis Fondasi yaitu Fondasi dangkal dan Fondasi dalam. Fondasi dalam yang biasa juga disebut dengan Fondasi tiang memiliki daya dukung yang ditentukan berdasarkan tahanan ujung (end bearing) dan pelekatan tiang dengan tanah (friction). Dengan adanya daya dukung tersebut, maka Fondasi akan menahan semua beban pada bangunan seperti beban lateral (horisontal) dan beban gravitasi (vertikal). Pada struktur bangunan yang memiliki beban besar seperti tower pada umumnya harus memeperhitungkan beban yang dapat diterima dan dipikul oleh Fondasinya karena perngaruh perbandingan antara ketinggian dan lebar struktur yang sangat besar (langsing). Pada perencanaan tower, beban lateral sangat berpengaruh dalam perhitungan Fondasi tower tersebut, hal ini merupakan sesuatu yang harus di perhitungkan untuk melihat kapasitas Fondasi dalam menopang beban struktur dan beban yang bekerja pada tower. Dalam mendesain Fondasi tower perlu diperhatikan juga kondisi tanah yang berada di bawah Fondasi tersebut apakah cukup kuat untuk menopang beban yang berada diatasnya. Anilisis untuk kelompok tiang mempunyai banyak metode salah satunya adalah analisis pushover, merupakan salah satu komponen performance based design yang menjadi sarana untuk mengetahui kapasitas suatu struktur. Dasar dari metode ini sangat sederhana, yaitu memberikan pola beban statik tertentu dalam arah lateral yang besarnya ditingkatkan secara incremental sampai struktur tersebut mencapai target displacement tertentu atau mencapai pola keruntuhan tertentu. Dari hasil analisis, dapat digambarkan hubungan antara base shear dan roof displacement, hubungan tersebut kemudian dipetakan sebagai kurva kapasitas struktur. Selain itu, analisis pushover juga dapat memperlihatkan secara visual perilaku struktur pada saat kondisi elastis, plastis dan sampai terjadinya keruntuhan pada elemen-elemen strukturnya. Dengan metode spektrum kapasitas berdasarkan peraturan ATC-40 Meskipun metode pushover ini sangat sederhana, informasi yang dihasilkan sangat berguna karena mampu menggambarkan respons in-elastis bangunan ketika mengalami gempa. Analisis ini memang bukan cara yang terbaik untuk mendapatkan jawaban terhadap masalah-masalah analisis dan desain, tetapi cara ini relatif sederhana untuk mendapatkan respon non-linier suatu struktur. Penggunaan instrumentasi pada pengujian tiang menjadi salah satu metode yang dapat diandalkan untuk mengetahui informasi tentang interaksi tanah dengan tiang. Di samping itu, dengan adanya program (software) geoteknik akan memudahkan dalam melakukan analisis Fondasi tiang untuk menghasilkan output yang diperlukan. Berdasarkan hal tersebut di atas, penelitian tugas akhir ini bertujuan untuk meneliti kapasitas daya dukung, perilaku transfer beban, dan beban-penurunan pada Fondasi tiang akibat pembebanan lateral berdasarkan hasil uji beban tiang yang berasal dari output dari program (software) geoteknik tersebut. 


\section{Batasan masalah}

Pada penelitian ini, ruang lingkup permasalahan dibatasi pada:

1. Menggunakan data penyelidikan tanah dan data laporan pengujian laboratorium, dan berasal dari salah satu proyek di daerah Kalimantan Timur.

2. Menganlisa kapasitas tiang pada gaya lateral hanya dengan metode puhsover.

3. Permodelan Fondasi tiang tower terhadap beban lateral dilakukan dengan salah satu software geoteknik.

4. $\quad$ Evaluasi terhadap Fondasi tiang tower berdasarkan 1 tiang, 2 tiang, dan 4 tiang

5. Menganalisa tiang pancang berbentuk kotak berdimensi 500x500mm, 400x400mm, 300x300mm serta menggunakan tulangan dan tanpa tulangan.

6. Analisa dilakukan terhadap efek beban lateral pada arah sumbu X.

\section{Rumusan masalah}

Rumusan masalah dalam penelitian ini adalah kapasitas untuk masing masing tiang pada kelompok tiang menggunakan metode pushover. Perhitungan dilakukan dengan mempertimbangkan kriteria-kriteria dalam melakukan seleksi terhadap beberapa alternatif yang ada dengan menggunakan salah satu program (software) geoteknik.

\section{Tujuan penelitian}

Penelitian ini memiliki beberapa tujuan, yaitu:

1. Mengetahui kapasitas pada tiang kelompok terhadap gaya lateral yang diberikan.

2. Mengevaluasi keamanan kapasitas daya dukung pada kelompok tiang.

3. mengetahui pengaruh jumlah tiang terhadap perilaku kelompok tiang akibat variasi beban lateral menggunakan program Allpile.

4. Mengetahui kekuatan maksimal kelompok tiang pada Fondasi tower akibat bertambahnya variasi gaya lateral yang diberikan.

5. Mengetahui performance point tiang berdasarkan dari metode pushover.

\section{TINJAUAN PUSTAKA}

\section{Analisa Pushover}

Analisa pushover (ATC 40,1997) merupakan salah satu komponen Performance based design yang menjadi sarana dalam mencari kapasitas dari suatu struktur.

\section{Kinerja Struktur Metode $A T C-40$}

Tingkatan kinerja dalam ATC-40 digambarkan dalam kurva kapasitas seperti pada Gambar 1, yaitu kurva yang menggambarkan hubungan antara perpindahan lateral dan total gaya geser dasar akibat gempa, " $V$ " pada struktur.

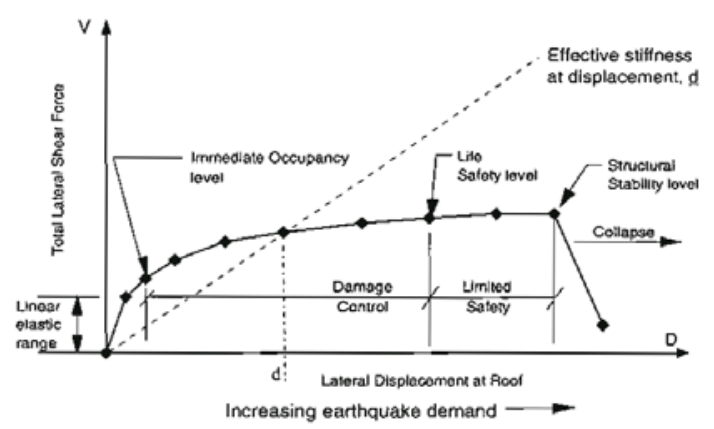

Gambar 1 Tipikal Kurva Kapasitas pada Berbagai Tingkat Kinerja Struktur

Kinerja seismik digambarkan dengan menetapkan tingkat kerusakan maksimum yang diizinkan (performance level) untuk mengidentifikasi bahaya gempa. Level kinerja Tabel 1 dapat dideskripsikan pada lagi berdasarkan kondisi bangunan pasca gempa dan kategori bangunan yang diizinkan terhadap level kinerja tertentu yang dapat dilihat pada Tabel 1. 
Tabel 1. Kondisi Bangunan Pasca Gempa dan Kategori Bangunan padaTingkat Kinerja Struktur

\begin{tabular}{|c|c|c|}
\hline Tingkat Kinerja & Kondisi Bangunan Pasca Gempa & Kategori Bangunan \\
\hline $\begin{array}{l}\text { SP-1 Immediate } \\
\text { Occupancy (IO) }\end{array}$ & $\begin{array}{l}\text { Bangunan aman saat terjadi gempa, resiko korban } \\
\text { jiwa dan kegagalan struktur tidak terlalu berarti, } \\
\text { gedung tidak mengalami kerusakan berarti, dan } \\
\text { dapat segera difungsikan kembali. }\end{array}$ & $\begin{array}{l}\text { Struktur bangunan yang mutlak } \\
\text { difungsikan sebagai sarana } \\
\text { penyelamatan, penyimpan barang } \\
\text { berbahaya, atau struktur bangunan } \\
\text { yang dapat mempengaruhi ekonomi } \\
\text { sosial. Contohnya rumah sakit, } \\
\text { gudang bahan bakar/bahan } \\
\text { berbahaya, dan lain-lain. }\end{array}$ \\
\hline $\begin{array}{l}\text { SP-2 Damage Control } \\
\text { (DC) }\end{array}$ & $\begin{array}{l}\text { Merupakan transisi antara Immediate Occupancy } \\
\text { (IO) SP-1 dan Life Safety (LS) SP-3. Bangunan } \\
\text { masih mampu menahan gempa yang terjadi, resiko } \\
\text { korban jiwa manusia sangat kecil. }\end{array}$ & $\begin{array}{c}\text { Struktur untuk bangunan bersejarah, } \\
\text { bangunan yang menjadi tempat } \\
\text { penyimpanan barang-barang } \\
\text { berharga. }\end{array}$ \\
\hline SP-3 Life Safety (LS) & $\begin{array}{c}\text { Bangunan mengalami kerusakan tetapi tidak } \\
\text { diperkenankan mengalami keruntuhan yang } \\
\text { menyebabkan korban jiwa manusia (resiko korban } \\
\text { jiwa sangat rendah). Setelah terjadi gempa maka } \\
\text { bangunan dapat berfungsi kembali setelah } \\
\text { dilakukan perbaikan komponen struktural maupun } \\
\text { non-struktural. }\end{array}$ & $\begin{array}{l}\text { Fasilitas-fasilitas umum, gedung } \\
\text { perkantoran, perumahan, gudang, dan } \\
\text { lain-lain. }\end{array}$ \\
\hline SP-4 Limited Safety & $\begin{array}{c}\text { Merupakan transisi antara } S P-3 \text { dan } S P-4 \text { dan bukan } \\
\text { merupakan tingkatan serta tidak memperhitungkan } \\
\text { aspek ekonomis dalam melakukan perbaikan pasca } \\
\text { gempa. }\end{array}$ & \\
\hline $\begin{array}{l}\text { SP-5 Structural } \\
\text { Stability (SS) }\end{array}$ & $\begin{array}{c}\text { Struktur pasca gempa mengalami kerusakan hingga } \\
\text { diambang keruntuhan total maupun parsial. } \\
\text { Komponen struktur penahan beban gravitasi masih } \\
\text { bekerja meskipun keseluruhan kestabilan sudah } \\
\text { diambang keruntuhan. }\end{array}$ & - \\
\hline SP-6 Not Considered & $\begin{array}{c}\text { Bukan merupakan tingkatan kinerja struktur, tetapi } \\
\text { hanya untuk melakukan evaluasi seismik non- } \\
\text { struktural atau retrofit. }\end{array}$ & - \\
\hline
\end{tabular}

Untuk mengubah kurva kapasitas ke dalam format $A D R S$ digunakan persamaan-persamaan

$$
\begin{gathered}
S_{a}=\frac{V / W}{\alpha_{1}} \\
S_{d}=\frac{\Delta_{\text {roof }}}{P F_{1} \phi_{\text {roof } .1}}
\end{gathered}
$$

Dengan diperoleh kurva demand spektrum menggunakan persamaan

$$
S_{d}=\frac{T^{2}}{4 \pi^{2}} S_{a} \cdot(g)
$$

Dalam ATC-40 redaman viscous ekuivalen dirumuskan dengan persamaan

$$
\begin{gathered}
\beta_{o}=\frac{63.7(\text { (ayDpi-Dyapi) }}{\alpha p i D p i} \\
\beta_{e q}=\beta_{o}+0,05
\end{gathered}
$$

\section{Batasan Deformasi Pushover analysis of underground structures}

Deformasi lateral pada saat performance point harus dicek terhadap deformasi limit yang ditetapkan dalam tabel pushover analysis of underground structures. Deformasi limit pada berbagai tingkat kinerja dilihat pada tabel 2 
Tabel 2 Storey drift Limits At Different Performance Levels And Damage State

(Sumber : Pushover Analysis Of Underground Stuctures, 2014 : 426)

\begin{tabular}{ccc}
\hline Performance Level & Damage State & Storey Drift \\
\hline Fully operational, immediate occupancy & No damage & $<0.2 \%$ \\
\hline Operational, damage control, moderate & Repairable & $<0.5 \%$ \\
\hline Life safe-damage state & Irreparable & $<1.5 \%$ \\
\hline Near collapse, limited safety, hazard reduced & Severe & $<2.5 \%$ \\
\hline Collapse & & $>2.5 \%$ \\
\hline
\end{tabular}

\section{Program untuk Analisis Pile}

Program berbasis (software) geoteknik ini adalah program yang menganalisis kapasitas beban tiang yang cukup akurat. Program (software) geoteknik ini dapat menangani beberapa jenis tiang pancang seperti: tiang bor, tiang pancang, tiang pancang pipa baja, tiang pancang, tiang pancang kayu, tiang pancang meruncing, tiang pancang, tiang dangkal pondasi, dll.

\section{METODOLOGI PENELITIAN}

\section{Pembahasan Awal}

Perhitungan menggunakan program berbasis geoteknik dikondisikan dalam beberapa kondisi pada pondasi tiang tower, yaitu pada kondisi :

1. Free head, kondisi dimana bagian atas pada tiang bisa dengan bebas berputar, seperti engsel. Kondisi ini diasumsikan tiang berada diantara pile cap.

2. Fixed head, kondisi dimana kepala tiang tidak dapat berotasi. Kondisi dimana tiang dan pile cap sudah terikat, dan terjadi momen pada kepala tiang.

3. No cap, kondisi dimana tiang tidak tersambung/terhubung dengan pile cap.

\section{Pengumpulan Data}

Objek penelitian pada penelitian ini berasal dari salah satu proyek yang bertempat di daerah Kalimantan Timur. Data tanah yang diambil digunakan untuk menganalisis studi tentang fondasi tiang tower.

\section{Pengelolahan Data}

Studi literatur diperlukan sebelum melakukan analisis perhitungan tersebut, seperti mencari dasar dasar teori dari sumber sumber data yang baik

\section{Pembahasan}

Dari data-data yang telah didapat dan telah terkumpul dilakukan perhitungan dalam pengaplikasian program berbasis geoteknik untuk mendapatkan hasil kelompok tiang pada tiang tower sehingga diketahui kapasitas masing masing tiang.

\section{ANALISIS DAN PEMBAHASAN}

\section{Data Lokasi}

Pada penyelidikan yang dilakukan di lokasi rencana bangunan di salah satu proyek daerah Kalimantan timur, yang terdapat 3 titik penyelidikan ditempatkan didaerah yang di perkirakan dapat mewakili kondisi tanah setempat. Berikut adalah potongan lapisan tanah DB-1, DB-2, dan DB1-B. 


\begin{tabular}{|c|c|}
\hline Zg-m & Soil Data Input \\
\hline$\overline{0}$ & $\overline{\bar{E}} \overline{\overline{ }}=$ Soft Clay \\
\hline 10 & $\overline{=}=\overline{=}$ Soft Clay \\
\hline 15 & 莘 Stiff Clay \\
\hline 25 & 莘 Stiff Clay \\
\hline 30 & Stiff Clay \\
\hline 35 & 坴 Stiff Clay \\
\hline 38 & 坴 Stiff Clay \\
\hline
\end{tabular}

Gambar 2 Kedalaman dan Lapisan Tanah

\section{Permodelan Pondasi Tower}

Tiang pancang yang digunakan berbentuk kotak dengan ukuran 500 x 500 mm, 400 x 400 mm, dan 300 x 300 mm. Tiang yang ditinjau akan dilakukan analisa pushover, dengan memberi gaya geser (shear stress) sampai beban maksimal yang bisa dihitung oleh program berbasi geoteknik tersebut

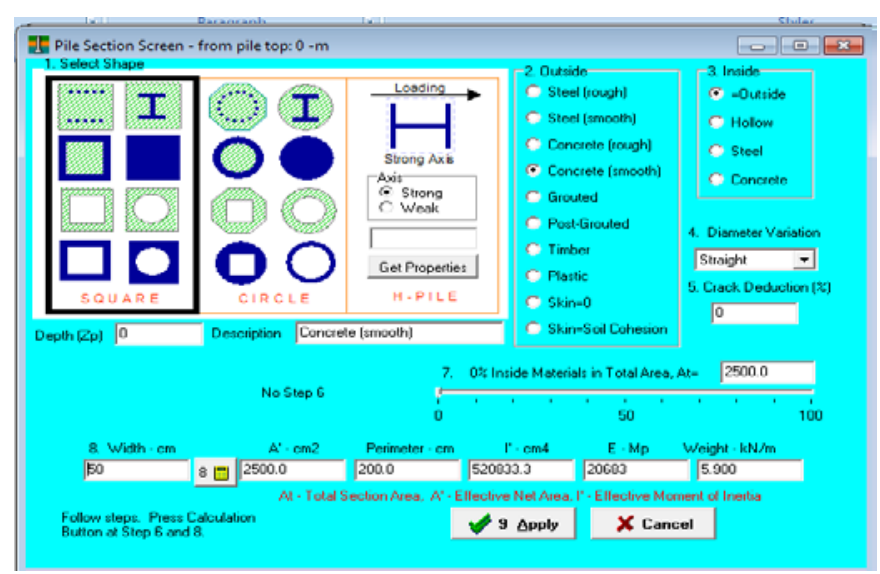

Gambar 3 Ukuran dan bentuk tiang yang digunakan

Analisa terhadap pondasi tower dilakukan juga terhadap 1 tiang , 2 tiang dan 4 tiang seperti gambar diatas. Masingmasing dari dimensi dan kondisi tiang dilakukan pengecekan terhadap 1 tiang, 2 tiang dan 4 tiang. Untuk kondisi free head dan kondisi fix head.

\section{Pembebanan pada pondasi tower}

Analisis pushover pada pondasi tower dengan memberikan beban arah lateral (horisontal) terhadap tiang, dengan beban ditambahkan secara bertahap sehingga mendapatkan kurva kapasitas. Untuk beban arah vertikal menggunakan beban dari menara SUTET (Saluran transmisi tegangan ekstra tinggi) yang berasal dari PT PLN.

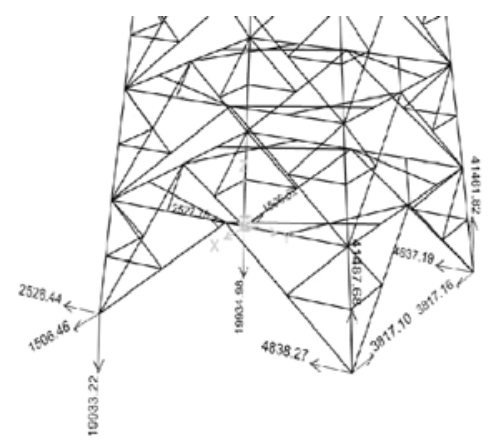

Gambar 4 Pembeban dari menara SUTET 


\section{Analisis Pushover Terhadap Pondasi Tower}

Kurva kapasitas didapatkan dari hasil analisis pushover, dengan beban yang dimasukan secara bertahap terhadap pondasi. Pada kepala tiang di lihat displacement yang terjadi sehingga didapatkan Kurva kapasitas pada masing masing tiang.

\section{Analisis Terhadap 1 Tiang}

Analisa dilakukan pada setiap jumlah dengan analisis pushover yang dilakukan pada setiap kondisi dan setiap dimensi, juga di lakukan dengan menggunakan tulangan dan non-tulangan.

Kondisi Free Head dengan dimensi 500 x 500 mm :

Tabel 3 Output Shear \& Deflection 500 x 500 mm (tanpa tulangan)

\begin{tabular}{ccc}
\hline Deflection $(\mathrm{cm})$ & $\mathrm{P}(\mathrm{kN})$ & $\mathrm{Q}(\mathrm{kN})$ \\
\hline 0 & 0 & $-414,88$ \\
\hline 0,48 & 50 & $-414,88$ \\
\hline 3,65 & 150 & $-414,88$ \\
\hline 17,7 & 250 & $-414,88$ \\
\hline 56,1 & 350 & $-414,88$ \\
\hline 80,7 & 400 & $-414,88$ \\
\hline 111 & 450 & $-414,88$ \\
\hline 148 & 500 & $-414,88$ \\
\hline
\end{tabular}

Dari data yang didapatkan dihitung perhitungan untuk kurva Sa vs Sd,

Tabel 4 Sa dan SD 500 x 500 mm (tanpa tulangan)

\begin{tabular}{cccccc}
\hline V(kN) & $\begin{array}{c}\mathrm{W} \\
(\mathrm{Kg})\end{array}$ & $\begin{array}{c}\mathrm{W} \\
(\mathrm{kN})\end{array}$ & Sa & Sa $(\mathrm{g})$ & Deflection $(\mathrm{cm})$ \\
\hline 0 & 21000 & 210 & 0 & 0 & 0 \\
\hline 50 & 21000 & 210 & 0,238 & 0,0242 & 0,48 \\
\hline 150 & 21000 & 210 & 0,7142 & 0,0728 & 3,65 \\
\hline 250 & 21000 & 210 & 1,1904 & 0,1214 & 17,7 \\
\hline 350 & 21000 & 210 & 1,6666 & 0,17 & 56,1 \\
\hline 400 & 21000 & 210 & 1,9047 & 0,1943 & 80,7 \\
\hline 450 & 21000 & 210 & 2,1428 & 0,2186 & 111 \\
\hline 500 & 21000 & 210 & 2,3809 & 0,2429 & 148
\end{tabular}

Dari hasil perhitungan yang di dapat, maka dibuat grafik Sa vs Sd dari tulangan dan tanpa tulangan.

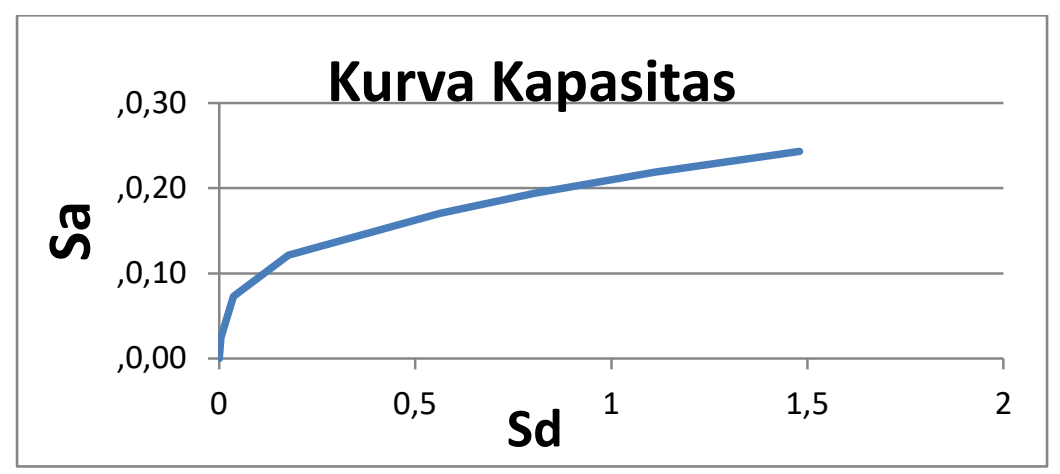

Gambar 5 Kurva kapasitas Sa vs Sd 500 x 500 mm (tanpa tulangan) 
Diperolehnya nilai Respons spektrum elastis pada redaman 5\% dari desain seismik, dan menggunakan hasil dari pushover tiang. Nilai respons spektrum yang direduksi akan didapatkan performance point dari masing masing tiang.

Tabel 5 Spectral Acceleration \& Spectral Displacement 500x500mm tanpa tulangan dan tulangan

\begin{tabular}{|c|c|c|c|}
\hline $\mathrm{T}$ (detik) & SA (g) & $\begin{array}{c}\text { Redaman } \\
5 \% \text { Sd (m) }\end{array}$ & SA baru \\
\hline 0 & 0,2432 & 0 & 0,1123 \\
\hline 0,2568 & 0,6079 & 0,01 & 0,2806 \\
\hline 0,5504 & 0,6079 & 0,0458 & 0,2806 \\
\hline 0,8439 & 0,6079 & 0,1076 & 0,2806 \\
\hline 1,1375 & 0,4903 & 0,1576 & 0,2866 \\
\hline 1,431 & 0,3897 & 0,1983 & 0,2278 \\
\hline 1,7245 & 0,3234 & 0,239 & 0,1891 \\
\hline 2,0181 & 0,2763 & 0,2796 & 0,1615 \\
\hline 2,3116 & 0,2412 & 0,3203 & 0,141 \\
\hline 2,6051 & 0,2141 & 0,361 & 0,1252 \\
\hline 2,8987 & 0,1924 & 0,4017 & 0,1125 \\
\hline 3,1922 & 0,1747 & 0,4424 & 0,1021 \\
\hline 3,4858 & 0,16 & 0,483 & 0,0935 \\
\hline 3,7793 & 0,1476 & 0,5237 & 0,0863 \\
\hline 4,0728 & 0,1369 & 0,5644 & 0,08 \\
\hline 4,3664 & 0,1277 & 0,6051 & 0,0747 \\
\hline 4,6599 & 0,1197 & 0,6457 & 0,07 \\
\hline 4,9534 & 0,1126 & 0,6864 & 0,0658 \\
\hline 5,247 & 0,1063 & 0,7271 & 0,0621 \\
\hline 5,5405 & 0,1007 & 0,7678 & 0,0589 \\
\hline 5,834 & 0,0956 & 0,8084 & 0,0559 \\
\hline 6,1276 & 0,091 & 0,8491 & 0,0532 \\
\hline 6,4211 & 0,0868 & 0,8898 & 0,0507 \\
\hline 6,7147 & 0,0831 & 0,9305 & 0,0486 \\
\hline 7,0082 & 0,0796 & 0,9711 & 0,0465 \\
\hline 7,3017 & 0,0764 & 1,0118 & 0,0447 \\
\hline 7,5953 & 0,0734 & 1,0525 & 0,0429 \\
\hline 7,8888 & 0,0707 & 1,0932 & 0,0413 \\
\hline
\end{tabular}

Sehingga mendapatkan hasil redaman 5\%, dapat membentuk kurva respons spektrum untuk redaman 5\% dan digabungkan dengan grafik spektrum kapasitas. 


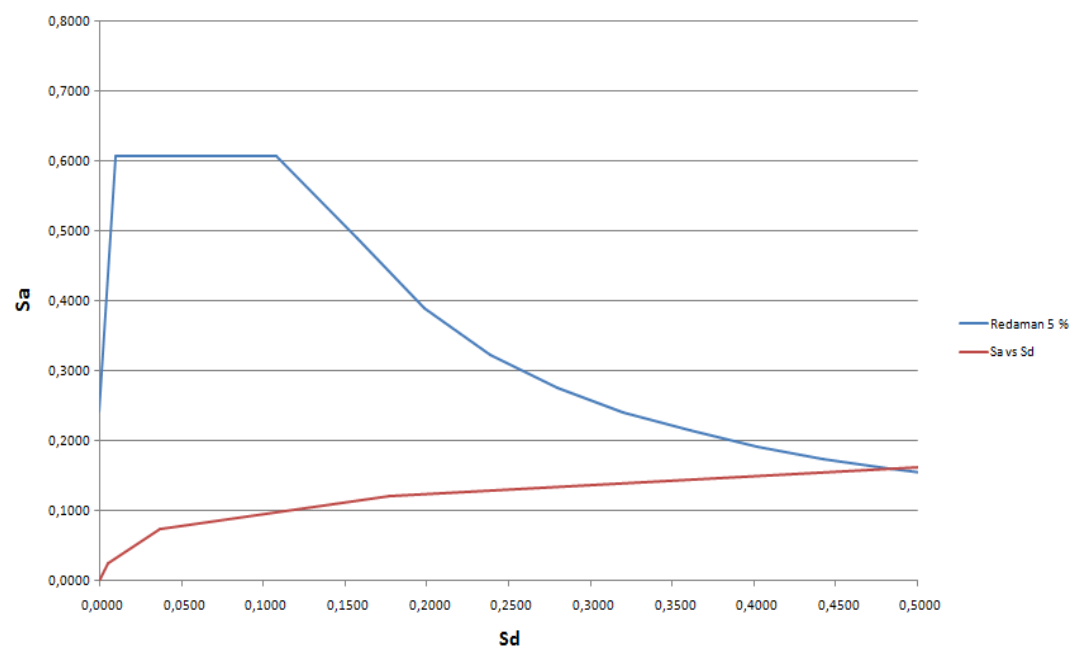

Gambar 6 Grafik Spektrum kapasitas dan redaman 5\% untuk tiang Free Head 500 x 500mm tanpa tulangan dan tulangan

Kemudian dari spektrum kapasitas tiang dan redaman $5 \%$ didapat nilai $\mathrm{a}_{\mathrm{y}}, \mathrm{d}_{\mathrm{y}}, \mathrm{a}_{\mathrm{pi}}, \mathrm{d}_{\mathrm{p} i}$. Kemudian dari hasil yang didapat dihitung nilai $\beta_{0}$, $\beta \mathrm{eq}$, SRA, SRV. Untuk nilai SRA dan SRV dari hasil perhitungan menggunakan rumus, dibandingkan dengan tabel minimum untuk SRA dan SRV sehingga hasilnya tidak boleh melebihi dari tabel minimum. Jika melebihi dari tabel minimum maka yang digunakan untuk nilai SRA dan SRV menggunakan nilai minimumnya.

Tabel 6 Minimum Allowable $S R_{A}$ And $S R_{V}$ values(Sumber: ATC-40, 1996)

\begin{tabular}{ccc}
\hline Structural Behavior Type & SRA & SRV \\
\hline Type A & 0.33 & 0.5 \\
\hline Type B & 0.44 & 0.56 \\
\hline Type C & 0.56 & 0.67
\end{tabular}

Dari perhitungan nilai Sra dan Srv pada tiang pondasi Type B maka dilakukan reduksi terhadap respons spektrum untuk redaman 5\%, dan didapat performance point untuk respons spektrum yang telah direduksi.

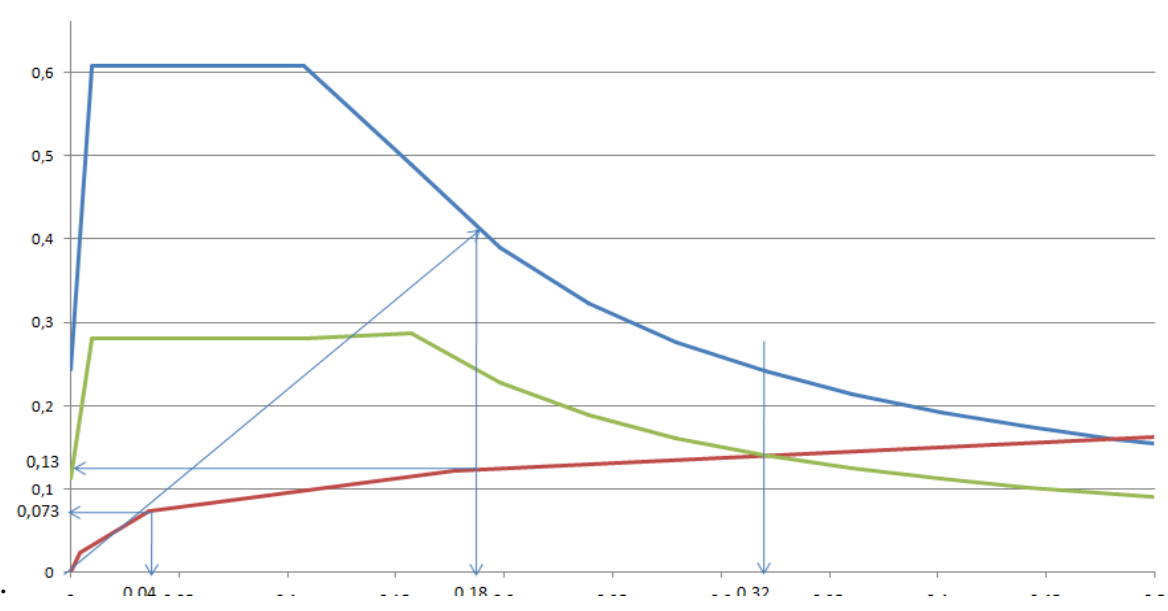

Gambar 7 Performance point dari kurva spektrum kapasitas dan respons spektrum

Diperoleh nilai performance point untuk tiang 500 x 500mm free head (tanpa tulangan) diperoleh dari perpotongan kurva kapasitas dengan kurva Sa (g) yang sudah tereduksi SRA / SRV. Kemudian dilakukan perbandingan dengan Tabel 2. 
Tabel 7 Nilai Performance point untuk jumlah 1 tiang dengan kondisi Fix Head

\begin{tabular}{|c|c|c|c|c|c|}
\hline Ukuran & $\begin{array}{l}\text { Displacement } \\
\text { (m) }\end{array}$ & $\begin{array}{c}\text { performance } \\
\text { point }\end{array}$ & $\begin{array}{l}\text { pile drift } \\
\text { ratio }\end{array}$ & kategori & kesimpulan \\
\hline \multirow[b]{4}{*}{500} & & & & $0,01-0,02$ & damage control \\
\hline & 35 & 0,18 & 0,005142857 & $<1.5 \%$ & $\begin{array}{l}\text { life safe -damage } \\
\text { control, moderate }\end{array}$ \\
\hline & & & & 0,01 & immediet occupacy \\
\hline & 19,8 & 0,18 & 0,009090909 & $<1,5 \%$ & $\begin{array}{l}\text { life safe -damage } \\
\text { control, moderate }\end{array}$ \\
\hline \multirow[b]{4}{*}{400} & & & & 0,01 & immediet occupacy \\
\hline & 35 & 0,18 & 0,005142857 & $<1,5 \%$ & $\begin{array}{l}\text { life safe -damage } \\
\text { control, moderate }\end{array}$ \\
\hline & & & & $0,01-0,02$ & damage control \\
\hline & 16,6 & 0,18 & 0,010843373 & $<1,5 \%$ & $\begin{array}{l}\text { life safe -damage } \\
\text { control, moderate }\end{array}$ \\
\hline
\end{tabular}

Tabel 7 Nilai Performance point untuk jumlah 1 tiang dengan kondisi Fix Head (Lanjutan)

\begin{tabular}{|c|c|c|c|c|c|}
\hline Ukuran & $\begin{array}{l}\text { Displacement } \\
\text { (m) }\end{array}$ & $\begin{array}{l}\text { performance } \\
\text { point }\end{array}$ & pile drift ratio & kategori & kesimpulan \\
\hline \multirow[b]{4}{*}{300} & & & & 0,01 & immediet occupacy \\
\hline & 35 & 0,16 & 0,004571429 & $<0,5 \%$ & $\begin{array}{c}\text { operational, } \\
\text { damage controll } \\
\text { moderate }\end{array}$ \\
\hline & & & & $0,01-0,02$ & damage control \\
\hline & 15,2 & 0,16 & 0,010526316 & $<1,5 \%$ & $\begin{array}{l}\text { life safe -damage } \\
\text { control, moderate }\end{array}$ \\
\hline
\end{tabular}

\section{KESIMPULAN}

Berdasarkan analisis yang dilakukan, didapatkan beberapa hasil resume dari nilai batas-batas yang telah didapatkan disimpulkan bahwa :

1. Analisa berdasarkan metode pushover menggambarkan bahwa kinerja tiang untuk pondasi tiang tower akan menghasilkan variasi gaya lateral dan delfeksi yang berbeda beda, dimana jika semakin besar dimensi pada tiang dan semakin banyak jumlah tiang, variasi beban yang mampu di tahan akan semakin besar. Hasil defleksi dengan beban yang diterima akan semakin besar dan menghasilkan nilai performance point yang kecil.

2. Untuk analisis metode pushover pada pondasi tiang tower sutet yang menggunakan data tanah Kalimantan Timur dan berdasaran beban vertikal dari tower sutet yang perhitungkan (-199,35 KN dan 414,88 KN) pada 1 tiang, 2 tiang dan 4 tiang memiliki tingkat rata-rata performance level dan keamaan yang berbeda-beda. Untuk 1 tiang memiliki rata rata pada keadaan life safety-damage state, untuk 2 tiang berada ditingkat sedang atau moderate, dan untuk 4 tiang berada di tingkat immediate occupancy.

3. Berdasarkan batas-batas dari tabel simpangan kinerja struktur berdasarkan ATC-40 dibandingkan dengan tabel storey drift limit performance untuk struktur bawah tidak memiliki hasil yang tidak jauh berbeda.

4. Berdasarkan metode spektrum kapasitas, jika semakin besar diameter tiang dan dimensi pada pondasi tiang, maka hasil yang didapat untuk nilai performance point akan semakin kecil. Karena semakin kecil nilai nya maka tingkat keamanan pada stturktur pondasi tiang tersebut.

5. Semakin besar dimensi pada tiang maka semakin besar kedalaman displacemant pada tiang.

\section{DAFTAR PUSTAKA}

ATC-40. 1996. Seismic Evaluation and Retrofit of Concrete Buildings Volume 1.California: Applied Technology Council.

Badan Standardisasi Nasional. 2012. Tata Cara Perencanaan Ketahanan Gempa untuk Struktur Bangunan Gedung dan Non Gedung (SNI 1726:2012). Jakarta: Badan Standardisasi Nasional.

Ferdian, Tedy. 2013. Perencanaan Struktur Menara Listrik Tegangan Tinggi. Jurusan Teknik Sipil, Fakultas Teknik, Universitas Kristen Maranatha. 
